\title{
The role of $\mathrm{CT}$ in acute mesenteric ischemia
} Ioanna Galanou, Diego Milani, Claudia Conti, Eriberto Farinella, Micol Sole Di Patrizi*, Stefano Trastulli, Roberto Cirocchi, Valerio Mecarelli, Giammario Giustozzi and Francesco Sciannameo

\begin{abstract}
Address: Department of General and Emergency Surgery, Hospital S. Maria and University of Perugia, Terni, Italy
\end{abstract}
* Corresponding author

from XXI Annual Meeting of The Italian Society of Geriatric Surgery

Terni, Italy. 4-6 December 2008

Published: I April 2009

BMC Geriatrics 2009, 9(Suppl I):A52 doi:10.1 I86/I47I-23I8-9-SI-A52

This abstract is available from: http://www.biomedcentral.com//47I-23I8/9/SI/A52

(c) 2009 Galanou et al; licensee BioMed Central Ltd.

\section{Background}

Acute mesenteric ischemia is not a frequent abdominal emergency. The $90 \%$ mortality of this affection is related to a delayed diagnosis. Superior mesenteric artery embolism is the most frequent cause of mesenteric ischemia. In this study we analyzed the diagnostic role of CT in this disease.

\section{Materials and methods}

From 1998 until 200732 patients (18 women, 14 men) with a mean age of 62 years underwent operation for primary intestinal ischemia at our institution. The medical and surgical records and imaging studies were reviewed retrospectively.

\section{Results}

Only 12 patients (37.5\%) performed a preoperative diagnostic CT study, whereas in 20 cases $(62.5 \%)$ the intestinal ischemia was diagnosed during surgical exploration. The acute mesenteric ischemia caused primarily by occlusive superior mesenteric artery in 26 cases $(81.2 \%)$ and by venous thrombosis in 6 cases $(18.7 \%)$. Most of the embolus are located approximately $3-10 \mathrm{~cm}$ from superior mesenteric artery emergence. An arterial embolus can be detected like filling defect or like an abrupt interruption of vascular enhancement. Frequently a secondary venous thrombosis follows the arterial occlusion. CT shows a moderate intestinal wall thickening and inclusions in air signs of intestinal gangrene. Only 19 (59.3\%) of 32 patients survived the acute intestinal ischemia (in hospital mortality was $40.6 \%$ ), delayed diagnostic and operation caused higher mortality. In 12 cases a preoperative diagnostic CT was performed the mortality was $32.5 \%$.

\section{Conclusion}

According a difficult clinical diagnosis of acute mesenteric ischemia and the necessity of an early diagnosis we suggest to perform a CT at all patients with risk factors and acute abdominal pain for whom we have a clinical suspicious. 